


\section{About IJMA [last updated October, $\left.1^{\text {st }}, 2021\right]$}

$\checkmark$ International Journal of Medical Arts is the Official Journal of the Damietta Faculty of Medicine, AlAzhar University, Egypt

$\checkmark$ It is an International, Open Access, Double-blind, Peer-reviewed Journal

$\checkmark$ Published four times a year

$\checkmark$ The First Issue was published in July 2019

$\checkmark$ Published under the following license: Creative Commons Attribution-ShareAlike 4.0 International Public License (CC BY-SA 4.0). It had updated from the Creative Commons license [CC BY] in volume 2, Issue 4, October 2020 About IJMA

$\checkmark$ The Egyptian Knowledge Bank hosts the web site of IJMA

$\checkmark$ The Egyptian Knowledge Bank supports IJMA

$\checkmark$ IJMA follows the regulations of the International Committee of Medical Journal Editors

$\checkmark$ IJMA is indexed in the "Directory of Open Access Journals" [15 January 2021].

$\checkmark$ IJMA is indexed in J-Gate [29-6-2021]

$\checkmark$ IJMA is a member of the International Society of Managing and Technical Editors

$\checkmark$ Listed in "Index Copernicus", "Publons", "Academic resource index [ResearchBib]" "Electronics journal library", "Eurasian Scientific Journal Index", "WorldCat" Superstar Journal Database, and "Citefactor"

$\checkmark$ IJMA introduced to the search engine [BASE] through DOAJ

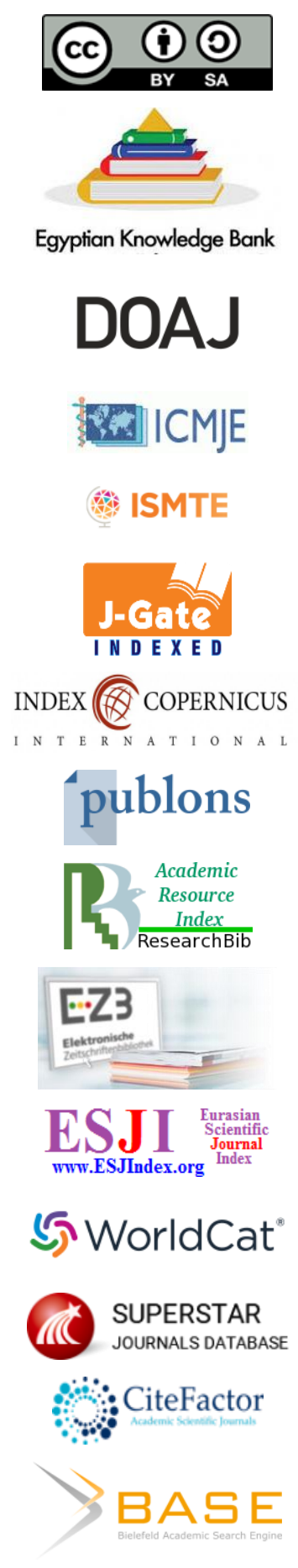




Available online at Journal Website
https://ijma.journals.ekb.eg/
Main subject [Vascular Surgery]

Original Article

\title{
Comparative Study between Conventional Stripping Surgery and Endovenous Laser Ablation in Management of Primary Lower Limb Varicose Veins
}

\author{
Abdallah Mohamed Ali [1], Ayman Fahmy Elramah [2], Mahmoud Mohammed Moawad [1] \\ 1 Department of Vascular Surgery, Damietta Faculty of Medicine, Al-Azhar University, Egypt \\ 2 Department of General Surgery, Damietta Faculty of Medicine, Al-Azhar University, Egypt \\ Corresponding author: Abdallah Mohamed Ali \\ Email: abdallahatallah40@gmail.com
}

Submission date: July 13, 2021; Acceptance date: November 6, 2021

DOI: $10.21608 / / J M A .2021 .86095 .1341$

DOAJ

ABSTRACT

Background: Varicose veins are among the commonest conditions encountered in daily vascular surgery practice. Endovascular laser ablation was introduced for its management wit an aim to reduce associated complications and recurrence of conventional surgery.

Aim of the work: To evaluate the safety and efficacy of endovenous laser ablation techniques versus conventional stripping surgery techniques as a method of treatment of primary lower limb varicose veins.

Patients and Methods: Forty patients were included, 20 for each group [conventional surgery and laser ablation]. All were assessed preoperatively; and preoperative, operative and post-operative data were documented. All patients were followed up for at least eight months.

Results: The majority of patients were in their forties with female sex predilection. Both groups were comparable regarding patient demographics, clinical presentation, CEAP Classification, clinical signs and preoperative duplex characteristics. Operative time was significantly shorter among laser than the surgery group [ $41.3 \pm 5.8 \mathrm{vs} 71.8 \pm 11.5$ min respectively]. Additionally, patients in laser group stayed for shorter durations in the hospital after intervention and returned earlier to their normal activity. Pain was significantly lower among the laser group [45\%] than the surgery group [75\%]. Recurrence was similar in both groups.

Conclusion: Endovascular laser ablation is superior to conventional stripping Surgery for the management of Primary Lower Limb Varicose Veins.

Keywords: Varicose veins; Endovascular; Laser; Stripping

This is an open-access article registered under the Creative Commons, ShareAlike 4.0 International license [CC BY-SA 4.0] [https://creativecommons.org/licenses/by-sa/4.0/legalcode.

Citation: Ali AM, Elramah AF, Moawad MM. Comparative Study between Conventional Stripping Surgery and Endovenous Laser Ablation in Management of Primary Lower Limb Varicose Veins. IJMA 2021; 3 [4] October-December: 1930-1940. [DOI: 10.21608/IJMA.2021.86095.1341].

${ }^{*}$ Main subject and any subcategories have been classified according to the research topic 


\section{INTRODUCTION}

Varicose veins [V] represent a common vascular problem that affects a significant number of the general population. The disease affects about $10-40 \%$ of $30-70$ years old people [1]. Previous trials have proposed that VV is more common among females, with a female to male ratio 3:1 [2].

Varicose veins are veins, which permanently lost its valvular action and constant dilatation with pressure, veins become elongated, tortuous and pouched [3].

The greater incidence of left-sided varicose veins that has been reported by some may be related to the left common iliac vein compression due to partial impedance of the venous return from the leg, where the right common iliac vein lies in the front of the sacral promontory ${ }^{[4]}$.

Truncal varicosities mean that the patient has poor functioning valves and dilatation of one or more of the truncal veins, the great saphenous vein and the small saphenous vein ${ }^{[5]}$.

The initial anatomic location of varicose veins is typically in the great and small saphenous distributions and their tributaries in the superficial system. Related risk factors are multiple, including primary etiologies associated with pregnancy, prolonged standing, female gender, and, rarely, congenital absence of valves [6].

Valvular incompetence and venous hypertension have been considered primary processes of varicosis. The classic theory of descending valve incompetence has the support of famous physicians ${ }^{[7]}$.

Duplex ultrasonography of the extremities is one of the most critical studies for evaluating and diagnosing venous insufficiency and thrombosis; currently, this imaging method, the "gold standard" for superficial venous imaging. Proper assessment comprises an evaluation of the reflux and obstruction in the deep, superficial, tributary, and perforating veins ${ }^{[8]}$.

Varicose veins comprise a progressive condition, except after gestation and delivery. During its course, VV leads to complications that usually propel the patient to seek medical advice. The most frequent comorbidities are thrombophlebitis, bleeding, eczema, and ulceration [9].

For many years, the standard $\mathrm{W}$ management was the surgical ligation and stripping of the affected vessel. The outcome has improved in recent decades due to enhanced understanding of the venous anatomy of the lower limb.
However, the recurrence rate is frequent [up to $20 \%$ and $30 \%$ [10].

The most notable endovenous advancements are the new widespread techniques of radiofrequency ablation [RFA] and endovenous LASER ablation [ELA]. These techniques may show superiority to stripping and conventional surgical ligation as well as less postoperative pain and recovery time [11]. The thermal energy generates heat and steam bubbles within the lumen of the target vein, destructing the endothelial lining of the vein. This leads to an inflammatory reaction leading to a thrombotic occlusion that efficiently closes off the lumen and finally leads to fibrosis [12].

Endovenous LASER ablation is considered safe and efficacious and recommended for the management of the saphenous reflux. Foam sclerotherapy is advised to treat telangiectasias, reticular veins, and extra-truncal VV. The use of endovenous LASER ablation may be advised over the use of foam sclerotherapy for the management of truncal reflux ${ }^{[13]}$. Sclerotherapy can be used to treat a different size of veins, although it is commonly used for the treatment of the smaller vessels, like the reticular veins and telangiectasias ${ }^{[10]}$.

\section{AIM OF THE WORK}

To evaluate the safety and efficacy of endovenous laser ablation techniques versus conventional surgery techniques as a method of treatment of primary lower limb varicose veins.

\section{PATIENTS AND METHODS}

This was a comparative study, conducted on patients presented by primary $\mathrm{V}$ of $\mathrm{LL}$. The surgery was completed at AL-Azhar University Hospital [New Damietta] during the duration from December 2020 to June 2021.

Inclusion criteria: The patient presented by unilateral or bilateral primary $\mathrm{V}$ of $\mathrm{LL}$, complaining of one or more of the following was included in the study: leg pain, varicosities, cosmetic disfigurement, leg ulcer, itching or pigmentation at LL, and incompetence SFJ and/or SPJ.

On the other side, the exclusion criteria were secondary LL VV, lower limb lymphedema, recurrent VV of LL, acute superficial thrombophlebitis of $L L, L L$ arterio-venous fistula [congenital or acquired], congenital anomalies of the venous system of $\mathrm{LL}$, general comorbidities, thrombosis of GSV [acute or chronic], LL skin infection, LL ischemia, LL malignancy, and drug hypersensitivity. 
Patients: Forty patients enrolled in this study. The patient in the study was divided into two groups: Group [A]: 20 patients had triple saphenectomy. Group [B]: 20 patients had Endovenous Laser ablation [ELA]. All patients were evaluated by full history taking, clinical examination and laboratory investigation to check of surgical fitness. These laboratory investigations included complete blood count, liver and kidney function test, and coagulation profile. In addition, all duplex ultrasound of the lower limb vascular system was done for all patients with an assessment of the great saphenous vein, small saphenous vein and extra axial varicosities [patency and diameters].

\section{Group [A]: Triple saphenectomy}

The GSV is approached through an oblique $2 \mathrm{~cm}$ incision in the groin crease. The incision started over the palpable femoral artery and then proceeded medially to assure suitable vision of the saphenofemoral junction and tributaries. The subcutaneous tissue was dissected to identify the GSV main trunk. The plane was extended to the SFJ. Each main tributary was ligated and divided, and GSV high ligation was done close to the femoral vein.

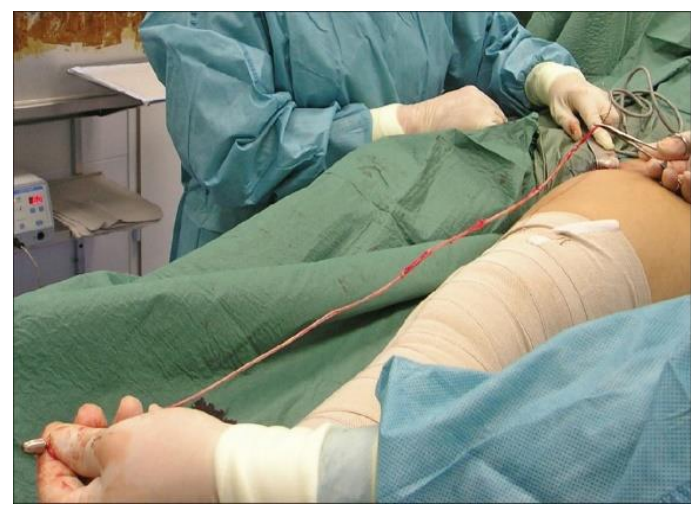

Figure [1]: Stripping of GSV [Al-Azhar University Hospital]

\section{Group [B]: [EVLA] endovenous laser ablation}

Color duplex US with an $8 \mathrm{MHz}$ probe was done in the upright position to detect incompetent sources and assign a mark over the skin covers GSV at the SFJ. GSV diameter was determined in upright position and documented. The technique was done in a well-prepared operative theater, assuring the safety precautions for using laser. The target limb was sterilized and draped. The patient was placed in anti-trendelenburg position to simplify the cannulation of GSV with an 18-gauge cannula. The patient position was then changed to the Trendelenburg position to start the manoeuvre. J-tip 0.035-inch guide wire was inserted under ultrasound direction up to the SFJ. A5-F long introducer sheath [up to $36 \mathrm{~cm}$ to $50 \mathrm{~cm}$ ] was position into the GSV
Double ligation was performed on the proximal stump. Caution was exerted to prevent femoral vein narrowing or leaving a long stump. GSV stripping was the central component of the operation for VV. The approach of stripping leaves normal distal veins for future grafting if indicated and prevents injury to the saphenous nerve. This results in less pain without compromising the overall outcome of the procedure. Incompetent accessory saphenous vein, if present, was ligated \& stripped during the procedure. After flush ligation was performed, the stripper end was passed after a transverse venotomy was created in the GSV at or below the level of the knee according to the presence of incompetent segment. The caudal incision was made transversely and the subcutaneous tissue was dissected. Stripping was done by the downward direction that is better for avulsion of tributaries and diminish injury to the saphenous nerve. Diseased leg was elevated to reduce bleeding and ecchymosis associated with stripping. Skin incisions were closed by proline 3-0 sutures, elastic stocking were immediately applied for one week, complete bed rest for 24 hours and early ambulation was recommended.

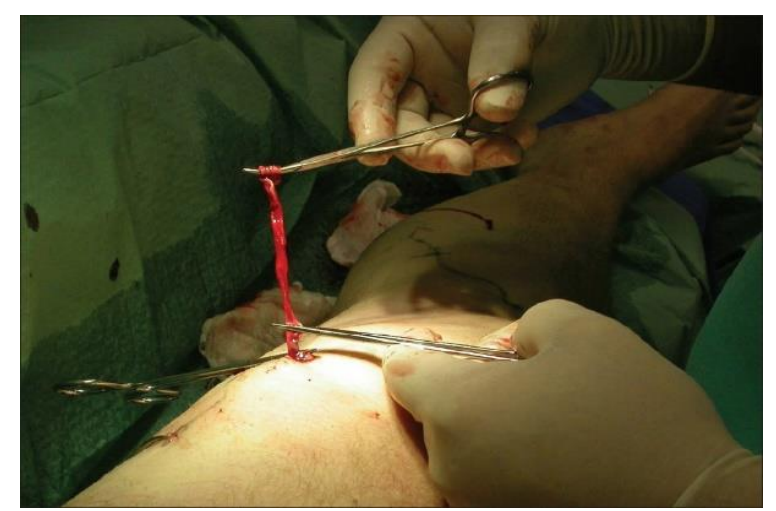

Figure [2]: Stab avulsion of blow outs [Al-Azhar University Hospital].

over the guide wire. The bare-tipped fibre 600 -Im diameter connected to a 980-nm diode laser was inseted through the sheath. The device was set with $10 \mathrm{~W}$ power and pulsed mode pattern 10 second [on] and one second [off]. The distal tip of the laser fibre was situated $2 \mathrm{~cm}$ below the SFJ confirmed by direct visualization of the red aiming beam of the laser fibre tip through the skin. Peri-venous tumescent anesthesia was applied to the fascial space around the GSV under cross-sectional US direction along its length. The amount of anesthetic solution was about $400-500 \mathrm{cc}$. The tumescent anesthesia composed of 20-25 ml lidocaine $2 \%$ buffered with $1.4 \%$ sodium bicarbonate in 500 cc saline $0.9 \%$. Then permitting the laser energy to be fired and the laser fibre and sheath were slowly pulled back untill they reached one centimetre above the site of puncture to 
prevent skin burns. Postoperatively, bandage compression was applied for 24 hours then patients were asked to wear full-thigh class II compression stockings [30-40 mm Hg] for one week. Patients were instructed to walk directly after the

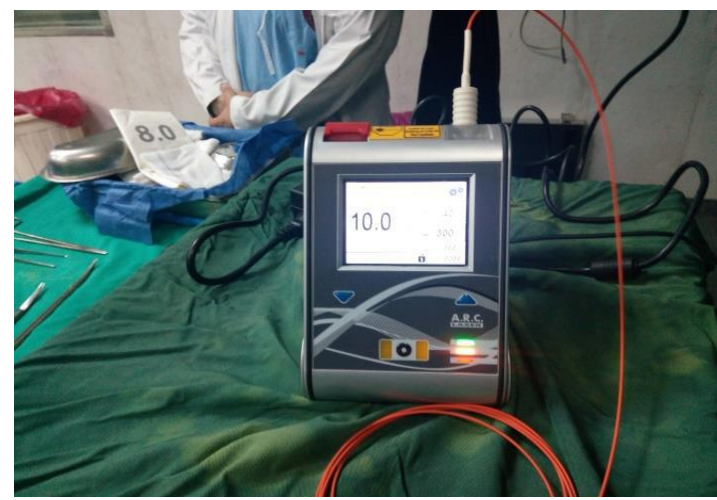

Figure [3]: Laser generator, Laser fibres

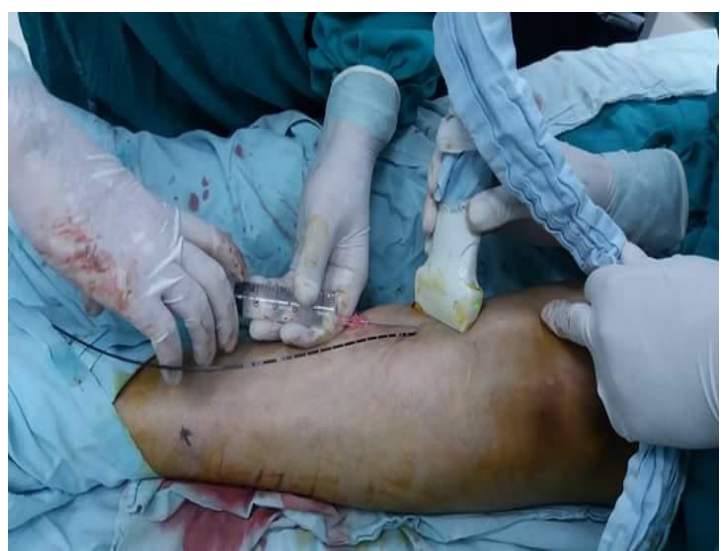

Figure [5]: Catheter inside GSV

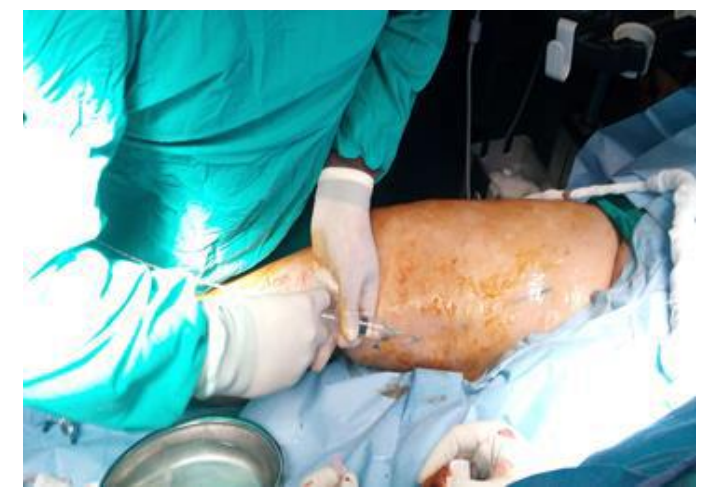

Figure [7]: Peri-venous tumescent anesthesia was injected into the fascial space surrounding the GSV under cross sectional sonographic guidance along its length

\section{Postoperative follow-up [at eight months]}

Clinical follow up for pain, subcutaneous hematoma, return to daily activity, recurrence, ecchymosis, infection, skin ulceration, burns, nerve injury, skin pigmentation and intervention and to continue their normal daily activities. All patients received routine non-steroidal anti-inflammatory drugs e.g. diclofenac potassium for one week.

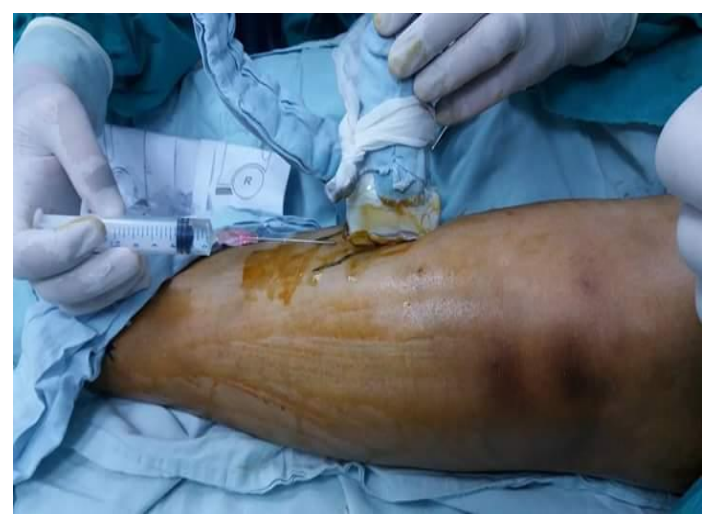

Figure [4]: Injection of tumescence

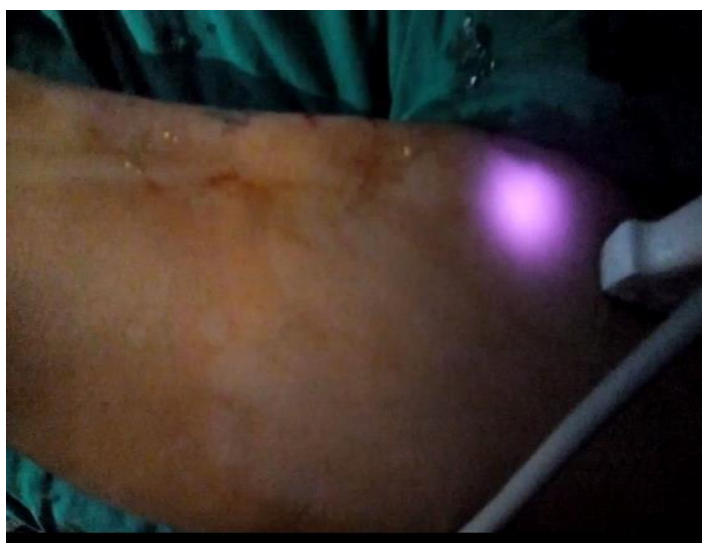

Figure [6]: The distal tip of the laser fibre was positioned $2 \mathrm{~cm}$ below the SFJ under duplex sonographic guidance

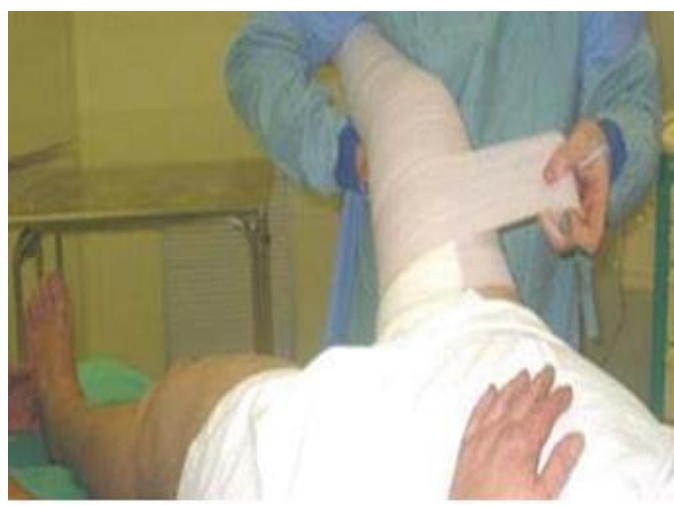

Figure [8]: Bandages compression

effect of healing of venous ulcer. Duplex ultrasound followup was done for early and late post-operative complications [after one month, three months and then after eight months] especially hematoma in surgery and GSV for [diameter, recanalization]. 


\section{Ethical considerations}

The study protocol was submitted for approval by the Institution Research Board [IRB] of the faculty of medicine, Al-Azhar University, Damietta [IRB 00012367-20-11-003]. Informed consent of the hospital authorities and informed verbal consent was obtained from each participant sharing in the study. Confidentiality and personal privacy were respected in all levels of the study. Collected data not be used for any other purpose.

\section{Statistical analysis}

The data for all patients was collected on a preprepared sheets, tabulated and analyzed by statistical package for social sciences [SPSS] version 21 [SPSS Inc, Chicago, USA]. For qualitative data, frequency and percent distributions were calculated. For quantitative data, mean, standard deviation [SD], were calculated. Groups compared by student " $\mathrm{t}$ " or chi square tests for quantitative and qualitative data respectively. $\mathrm{P}<0.05$ was considered significant.

\section{RESULTS}

\section{Demographic data}

The number of treated patients was 40 divided into 2 groups; twenty cases in each group. Group $[A]$ in which patients underwent surgical stripping there were 10 males $50 \%$ and 10 females $50 \%$, while there were 13 females [65\%] and 7 [35\%] males in group B [ laser group]. Patients in both groups were ranged from 17 to 42 years with a mean age $30.8 \pm 7.9$ in surgery group and $31.7 \pm 1.2$ in laser group. There was non- significant difference between two groups in age [Table 1].

\section{Clinical presentation}

All patients in both groups were presented with heaviness sensation in the lower limbs. In surgery group 16 patients [80\%] complained from pain, 11 complained from edema [55\%], 2 patients presented with venous ulcers [10 $\%$ ] and 4 patients complained from cosmetic issues [20\%]. while in laser group, there were 15 patients complained from pain [75\%], 12 cases complained of edema [60\%], one presented with venous ulcer [5\%] and 4 cases complained from cosmetic issues [20\%]. There was no significant difference between two groups in clinical presentation [Table 1].

Seventeen patients [ 9 patients in surgery group and 8 patients in laser group] were classified as CEAP class II, 16 patients were classified as CEAP class III [7 cases in surgery group and 9 cases in laser group], 4 patients were classified as CEAP class IV [2 patients in surgery group and 2 in laser group] and 3 patients were classified as CEAP class $V$ [2 patients in surgery group and one patient in laser group].There was no significant difference in the distribution of CEAP classification in both groups [Table 2].

\section{Clinical signs}

In the surgery group, 11 patients presented with right lower limb varicosities [55\%] and 9 patients were presented with left lower limb varicosities [45\%], while in laser group there were 9 patients presented with right side varicosities [45\%] and 11 presented with varicosities in the left side [55\%]. All patients in both groups suffered from saphenofemoral junction incompetence with GSV incompetence and reflux. There were 9 cases in surgery group suffered from incompetent perforators [45\%] and 8 cases in laser group [40 \%] suffered from incompetent perforators. There was no significant difference in side of varicosities and site of incompetence in both groups [Table 2].

Preoperative venous duplex revealed that the GSV diameter in our study ranged from $6 \mathrm{~mm}$ to $12 \mathrm{~mm}$ in both groups with a mean vein diameter $8.9 \pm 1.5 \mathrm{~mm}$ in surgery group and $8.2 \pm 1.6[\mathrm{~mm}]$ in laser group. The extension of diseased segment of GSV was below the knee in 18 cases in surgery group [90\%] and in 15 cases in laser group [75 $\%$ ], while it was limited to the thigh in 2 cases in surgery group [10\%] and 5 cases in laser group [25\%] [Table 2].

\section{Operative data}

Spinal anesthesia was used in all patients in both groups. Operative time in surgery group ranged from 49 minutes to 93 minutes with a mean time [71.8ะ11.5] minutes, while it was between 29 minutes and 50 minutes in laser group with a mean time [41.3 \pm 5.8$]$ minutes. There was a significant difference in operative time in both groups with $P$ value $\leq 0.001$. In addition, there was no major intraoperative complication in both groups. In the surgical group there were 2 cases complicated with intraoperative bleeding due to avulsion of tributaries during high ligation of GSV at the saphenofemoral junction. While in laser group, one case complicated with failure of below the knee access and was replaced by the above the knee puncture site with surgical ligation of infragenicular portion, as they were multiple tributaries in below knee portion making the wire hard to pass [Table 3].

The hospital stay and ambulation time after the procedures were recorded to compare between both groups. In surgery group, hospital-stay ranged from 24 hours to 48 hours with a mean time $32.7 \pm 6.6$ hours, while 
in laser group hospital stay time was ranged from 7 hours to 18 hours with a mean time $10.9 \pm 2.7$ hours. There was a significant difference between two groups with $P$ value $\leq$ 0.001 . Also, there was a significant difference between two groups in return to daily activity with $P$ value $\leq 0.001$. In surgery group, it took a time ranged between 5 and 8 days with a mean time $5.9 \pm 1.3$ days, while this took a time ranged between 1 and 4 days in laser group with a mean time $2.3 \pm 0.9$ days [Table 3 ].

\section{Post-operative complications}

In surgery group, there were fourteen patients with no reported complications, 3 patients complained of scars of groin incision and incisions of perforator's ligation. Three cases reported with edema which improved with usage of elastic stocking within 2-3 weeks. Two cases complicated with post stripping hematomas which were managed conservatively. On the other hand, there were no complications occurred in 16 cases in laser group 2 cases were complicated by burn and pigmentations in the form of mild to moderate erythema along the infragenicular portion of GSV which might be due to insufficient tumescent injection and very superficial segment of GSV. The two cases improved with conservative treatment. Two cases complained of edema and managed by elastic stocking. Only one case suffered from DVT in the posterior tibial vein and popliteal vein and might be caused by patient factors such as obesity and delayed ambulation. This condition was improved with full anticoagulation. There was a nonsignificant difference between two groups in post-operative complications [Table 3].

Regarding post-operative pain, all patients in both groups was managed by non-steroidal anti-inflammatory drugs. Five patients in laser group complained of persistent pain for one week post operatively, while there were 15 patients in surgery group complained of post-operative pain, 11 was controlled by analgesic and 4 patients suffered from paranesthesia for one month and might be caused by the saphenous and sural nerve affection during stripping. There was a significant difference in postoperative pain between two groups [Table 3]. Regarding patient's satisfaction, We found that 6 patients in the surgical group were not satisfied with the results due to paresthesia that lasts for relative long time [4 cases], groin scar [one case] and hematoma along the course of stripped GSV [one case], while there were 3 cases not satisfied with results in laser group due to burn and pigmentations. There was no significant difference between two groups [Table 3].

\section{Follow up}

Short term technical success is defined as the successful occlusion of the vein lumen. Immediate vein occlusion with lack of spontaneous \& augmented flow demonstrated by duplex US and vein wall thrombosis was achieved in all patients. No cases of failure of vein occlusion [in laser group] saphenofemoral ligation [in surgery group] were identified at the time of the procedure by the completion of duplex US scan. Follow up was done at one month, 3 months, and 8 months. This was done by clinical evaluation and duplex US. There was a nonsignificant difference between both groups. At one month, only one case in surgery group presented with the presence of saphenavarex. Also, in laser groups there was one case presented with recanalization of the proximal part of GSV with the presence of heaviness sensation. After three months, the same radiological results were found in both groups with a remarkable improvement in the manifestation in patients underwent both surgery and laser procedures. After eight months, duplex US was performed for all patients. In the surgery group there were 2 cases with recurrence, one case presented with saphenavarex and another case presented with superficial varicosities in the back of the knee joint with the absence of any complaint in both patients, while duplex US that was performed for the laser group reveled there were two cases presented with recurrence, one presented with recanalized the proximal part of GSV and another case complaint of incompetent perforators around medial malleolus. There was no significant difference between two groups [Table 3].

Table [1]: Demographics and clinical presentation of studied patients

\begin{tabular}{|c|c|c|c|c|}
\hline \multicolumn{2}{|c|}{ Variable } & Surgery [n=20] & Laser [n=20] & P value \\
\hline \multicolumn{2}{|l|}{ Age [years] } & $30.8 \pm 7.9$ & $31.7 \pm 1.2$ & 0.7 \\
\hline \multirow[t]{2}{*}{ Sex } & Male & $10[50.0 \%]$ & 7 [35.0\%] & \multirow{2}{*}{0.3} \\
\hline & Female & $10[50.0 \%]$ & $13[65.0 \%]$ & \\
\hline \multirow{5}{*}{$\begin{array}{l}\text { Clinical } \\
\text { presentation }\end{array}$} & Pain & 16 [80.0\%] & $15[75.0 \%]$ & 0.71 \\
\hline & Edema & $11[55.0 \%]$ & $12[60.0 \%]$ & 0.74 \\
\hline & Ulcer & $2[10.0 \%]$ & $1[5.0 \%]$ & 0.50 \\
\hline & Heaviness & $20[100.0 \%]$ & 20 [100.0\%] & 1.0 \\
\hline & Cosmetic & $4[20 \%]$ & $4[20 \%]$ & 1.0 \\
\hline
\end{tabular}


Table [2]: CEAP classification, clinical signs and preoperative duplex among studied groups

\begin{tabular}{|c|c|c|c|c|}
\hline \multicolumn{2}{|r|}{ Variables } & Surgery [n=20] & Laser $[n=20]$ & Pvalue \\
\hline \multirow{4}{*}{$\begin{array}{l}\text { CEAP } \\
\text { classification }\end{array}$} & $\mathrm{C} 2$ & $9[45 \%]$ & $8[40 \%]$ & 0.88 \\
\hline & C3 & $7[35 \%]$ & $9[45 \%]$ & \\
\hline & C4 & $2[10 \%]$ & $2[10 \%]$ & \\
\hline & C4 & $2[10 \%]$ & $1[5 \%]$ & \\
\hline \multirow[t]{2}{*}{ Side } & Right & $11[55 \%]$ & $9[45 \%]$ & 0.74 \\
\hline & Left & $9[45 \%]$ & $11[55 \%]$ & \\
\hline \multirow{2}{*}{$\begin{array}{l}\text { Site of } \\
\text { incompetence }\end{array}$} & GSV only & $11[55 \%]$ & $12[60 \%]$ & 0.50 \\
\hline & GSV + perforators & $9[45 \%]$ & $8[40 \%]$ & \\
\hline \multirow{3}{*}{$\begin{array}{l}\text { Preoperative } \\
\text { duplex }\end{array}$} & Vein diameter [mm] & $8.9 \pm 1.5$ & $8.2 \pm 1.6$ & 0.10 \\
\hline & Vein $\quad$ Below the knee & $18[90 \%]$ & $15[75 \%]$ & 0.20 \\
\hline & Level of the. Knee & $2[10 \%]$ & $5[25 \%]$ & \\
\hline
\end{tabular}

Table [3]: Operative and postoperative data amogn studied pateitns

\begin{tabular}{lcccc}
\hline & Variables & Surgery [n=20] & Laser [n=20] & P value \\
\hline Operative time & & $71.8 \pm 11.5$ & $41.3 \pm 5.8$ & $<0.001^{*}$ \\
Operative & No complication & $18[90 \%]$ & $19[95 \%]$ & 0.7 \\
complications & Failed access & $0[0 \%]$ & $1[5 \%]$ & 0.2 \\
& Bleeding & $2[10 \%]$ & $0[0 \%]$ & 0.5 \\
Hospital stay [hours] & & $32.7 \pm 6.6$ & $10.9 \pm 2.7$ & $<0.001^{*}$ \\
Return to normal activity [days] & & $5.9 \pm 1.3$ & $2.3 \pm 0.9$ & $<0.001^{*}$ \\
Postoperative & No complication & $14[70 \%]$ & $16[80 \%]$ & 0.5 \\
complications & Scar & $3[15 \%]$ & $0[0 \%]$ & 0.1 \\
& Hematoma & $2[10 \%]$ & $0[0 \%]$ & 0.2 \\
& Edema & $3[15 \%]$ & $2[10 \%]$ & 0.5 \\
& Burn & $0[0 \%]$ & $2[10 \%]$ & 0.2 \\
& DVT & $0[0 \%]$ & $1[5 \%]$ & 0.5 \\
Patient satisfaction & Pigmentation & $0[0 \%]$ & $2[10 \%]$ & 0.2 \\
Recurrence & Pain & $15[75 \%]$ & $5[45 \%]$ & $0.002^{*}$ \\
& & $14[70 \%]$ & $17[85 \%]$ & 0.20 \\
& Recurrence After one month & $1[5 \%]$ & $1[5 \%]$ & 1.0 \\
& Recurrence after three months & $1[5 \%]$ & $1[5 \%]$ & 1.0 \\
& Recurrence after eight months & $2[10 \%]$ & $2[10 \%]$ & 1.0
\end{tabular}

\section{DISCUSSION}

In the current study, female predominance was a remarkable as it represents about $57.5 \%$ of patients. This may be due to the cosmetic point of views which pushes females to seek medical advice earlier than males. These data are nearly similar in all recent studies. Although male persons tend to stand longer time times and exert more effort, but there is awareness among populations about this disease and its side effect which considered as motivation to a lot of females to seek medical care. However, these results are in contradiction to Basavarajappa et al. ${ }^{[14]}$ who reported that, of 222 patients, 162 were males and 60 were females with male to female ratio of $3: 1$. This could be explained by different inclusion criteria, and study sample size. But, Nishibe et al. ${ }^{[15]}$ reported similar female sex predominance as in the current work. They included a total of 140 patients [ 58 males and 82 females].
In the current research, out patients were in and around their forties, with no significant difference between groups. This was to lower than previous studies. Christenson et al. [16] had published a study on 200 cases, one hundred cases in each group, and the mean age was 45 in the laser group and 46 in in the patients underwent surgical ligation and stripping. Pronk et al. [17] published his study which was done on 130 patients and also had documented older mean age which was 50 years in the surgical group, and 49 years in the laser group. There was no definite cause for this difference between studies, but this can be explained by increase social awareness about symptoms and signs of varicose veins that push people for scanning of varicose veins.

All patients in our study were presented with heaviness sensation in the lower limbs. Pain was reported by $77.5 \%$, edema in $62.5 \%, 7.5 \%$ with ulcers, and $20.0 \%$ with cosmetic issues. Most of previous studies mentioned 
comparable presentations. Ash and Moore [18] documented 200 limbs, all of them complained from pain, and $89 \%$ suffered from heaviness. Kalteis et al. [19] published a study on 95 patients, $61 \%$ and $75 \%$ of patients in both laser and surgical groups respectively complained from heaviness. However, only $4 \%$ of the laser group and $8 \%$ of the surgical group suffered from pain in their lower limbs. This can be explained by the difference between the first times of the first visit to the clinic. On the other hand, different studies show that cosmetic issues had a main role as a motivation for patients to seek intervention. For example, Pronk et al. ${ }^{[17]}$ mentioned that some patients about $20 \%$ underwent endovenous laser ablation and surgical stripping present mainly with disfigurement and seek for intervention.

Mozafar and Khashayar [20] also documented $85 \%$ of patients underwent surgical high ligation in their study and $92.3 \%$ of patients in the thermal ablation group had cosmetic issues which need intervention.

CEAP classification usually considered as a corner stone in process of clinical sign categorization. Most of studies documented that most patients were CEAP II and CEAP III classification. In 2010, Rasmussen et al. [21] showed that $85 \%$ of patients were CEAP 2 and CEAP 3. Carradice et al. [22] documented their results in 2011, as patients presented with CEAP 2 were about $69 \%$ and patients with CEAP 3 were $31 \%$ of total patients .

Regrading operative data, Kalteis et al. [19] had published that mean operative time was 67 minutes needed to accomplish laser ablation for GSV with reflux, while surgical intervention need 65 minutes as a mean operative time. Rautio et al. [13] had published his research in 2002 with mean operative time of 99 minutes and for the surgical group and 115 minutes for the laser ablation group. This may be due to technical difficulties during the beginning of operation to get accurate venous axis, and long-time taken by the device to perform sufficient thermal ablation. However, different result was noticed in our study regarding operative time. In the surgical group, the mean operative time was 72 minutes, while in the laser group it was 41 minutes. This result can be explained by the recent popularity of this technique that allow accurate preoperative assessment of the vein by duplex ultrasound, well trained and skilled surgeons who can perform accurate and fast venous cannulation with the aid of ultrasound and revolution happened in devices abilities that can perform sufficient venous ablation in less time.

Unlike most of studies, there was a significant difference between two groups was documented in our study regarding hospital stay. The mean time was 32.7 hours with SD 6.6 hours in surgery group, while it is
$10.9 \pm 2.7$ hours in the laser group with $P$ value $\leq 0.001$. This difference could be explained.by the presence of wound in the surgical group which needed dressing and follow up to observe any hematoma in tack of GSV or in the groin incision.

Pronk et al. [17] showed that all patients included in the study were discharged in the first day post operatively. Another study also had similar results with no significant difference between the surgical and the laser groups regarding hospital stay [23].

Return to normal activities after surgery is of the great importance to patients. They usually care about the time needed to resume usual life style they used to do before surgical intervention. Kalteis et al. ${ }^{[19]}$ documented that patients underwent laser ablation needed longer time to return to daily activities than patients who underwent surgical ligation of saphenofemoral junction and stripping. Despite that complications following the laser ablation were less severe, a significant difference was marked in ambulation time after intervention, that is why sick leave could not be a real indicator of clinical outcome.

Other studies also had the same opinion about time needed to return to normal activity after intervention. A longer time was needed in the laser ablation group. The explanation was usage of endovenous wave length 810 , 940 \& $980 \mathrm{~nm}$ with bare tip catheters which might cause vein wall perforation and usually associated with a higher rate of complications. Recently, new devices with wave length $1470 \mathrm{~nm}$ with radial fibre are used to gain better results with less side effects [24]. Socio-economic status also plays a great role in the determination of the time needed to return to daily activities after intervention, so the procedure itself could not be the only factor that affects time needed to return to normal activity [25]

On the other hand, Pronk et al. [17] had different result in their study published in 2010. They noticed that there was no significant difference between the surgical intervention and the laser ablation groups. Mean time needed to return to normal activity was 3.2 with SD 4 in patients underwent conventional surgery while it was 3.2 with SD 4.3 in patients group who underwent laser ablation. Assadian et al. [26] also showed that, there was no significant difference between both groups regarding the ambulation time with slight privilege in the laser ablation group.

According to our study, there was a significant difference between both groups regarding time needed for return to normal activity with $P$ value $<0.001$. In surgery group, it took a time ranged between 5 to 8 days with a mean time [5.9 \pm 1.3 ] days, while this took a time ranged 
between one to 4 days in the laser group with a mean time $[2.3 \pm 0.9]$ days. This variation could be explained by variation of patient's socio-economic levels, nature of their jobs and cultural factors because patients considered operations with surgical wound as a major surgery need a long time of rest and rehabilitation. Similar to our results, Gloviczki et al. [27] reported that patients of the laser ablation group returned back to their normal life style 3 days earlier than patients of conventional surgery group.

In agreement with the current study, Siribumrungwong et al. [28] reported that patients treated with the surgical ligation of SFJ had higher rates of hematoma compared with who were treated with the laser ablation. Postoperative pain also was less sever in EVLA than surgical intervention. It is announced that wound infection is less in the laser ablation group by $60 \%$ compared with the incidence of infection in patients underwent the surgical ligation of SFJ and stripping. This study also mentioned that EVLA had a lower incidence of hematoma formation and pain on day 0 to day 7 following the procedures was less in the laser group. Different results had been published by Pronk et al. [17]. They found that post-operative pain on day 14 was more severe in patients underwent laser ablation. They explained this result as a device used with wavelength of $810 \mathrm{~nm}-980 \mathrm{~nm}$ usually cause affection to adjacent tissues and increase possibilities of post-operative complications.

Recurrence remains a significant problem after either endovenous laser ablation or surgical ligation and stripping. After the surgical intervention, neovascularization in the subcutaneous tissue around the saphenofemoral junction can lead to recurrence ${ }^{[29]}$.

The process of neovascularization may be associated with groin incision. The presence of non-competent tributaries after ligation is another possible cause for recurrence. In general, recurrence is caused by a connection between the remaining segment of GSV and new vessels or incompetent tributaries [30].

We agreed with Bush et al. [30] that the most important factors associated with varicose veins recurrence included new or recurrent perforator veins incompetence, recanalized GSV and reflux in anterior accessory great saphenous vein. Other published studies show similar results. The authors documented that patients managed by EVLA had the same risk of recurrence as patients who were underwent the surgical ligation of SFJ and stripping.

In a review presented by McBride [31] confirmed that endovenous techniques were as effective as standard surgery, but in the most of comparative data presented
EVLA was better regarding post-operative complications, pain and return to normal activity.

However, some studies demonstrated that the endovenous techniques had a lower rate of recurrence. Pronk et al. ${ }^{[17]}$ announced that, patients treated with the endovenous laser ablation had $40 \%$ less risk than surgery patient to have recurrent varicosities. This can be explained by the study done by Kianfard et al. ${ }^{[32]}$, as they did not observe neovascularization in those patients who underwent the laser ablation versus $12 \%$ in those who were managed by the surgical stripping. The laser ablation maintains a permeable epigastric vein that protects against neovascularization by preserving physiological drainage of the abdominal wall.

Measurement of outcome of the procedures used to manage varicose veins cannot only rely on duplex ultrasound evaluation of ablated saphenous veins, it is also depending on patient's satisfaction which is based on many factors especially relive of symptoms, remission of pain, presence of post-operative pain and patient ability to return to normal life style and activities.

As in the current work, Winterborn et al. ${ }^{[33]}$ documented that up to one third of patients may remain unsatisfied in the long term after both surgical ligation and the laser ablation. On the other hand, there are many studies reported that both procedures had the same quality of life post operatively and similar satisfactory rates with slight privilege toward the laser ablation due to better cosmetic results ${ }^{[19,34]}$. Other studies reported that more than $90 \%$ of patients said they would recommend the endovenous ablation procedures to friends and relatives ${ }^{[35,36]}$.

The study limitations include the small number of patients included in each group, which prevents the globalization of the study results. In addition the short duration of follow up represented another limitation. These limitations warrant future studies on a large scale of patients for a long duration.

\section{CONCLUSION}

In short, our study results indicated that, endovascular laser ablation is superior to conventional stripping surgery for the management of Primary Lower Limb Varicose Veins. However, the recurrence rate is similar between both procedures.

\section{Financial and Non-financial Relationships and Activities of Interest}

None 


\section{REFERENCES}

1. DePopas E, Brown M. Varicose Veins and Lower Extremity Venous Insufficiency. Semin Intervent Radiol. 2018 Mar; 35 [1]: 56-61. doi: 10.1055/s-0038-1636522.

2. Sharma S, Vashist M, Vashist MG. Manifestation of Clinical Symptoms and Associated Complications in Varicose Veins: An Institutional Study. Indian J Public Health Res Develop. 2019; 481-486. DOI:10.37506/ v10/i12/ 2019/ijphrd/192000.

3. Khan SM, Ahmed S. A prospective study on etiology and clinical features of varicose veins: A hospital based study. Int J Surg. 2019; 3[4]: 06-10. DOI: 10.33545/surgery.2019.v3.i4a.209

4. Yang L, Liu J, Cai H, Liu Y. The clinical outcome of a one-stop procedure for patients with iliac vein compression combined with varicose veins. J Vasc Surg Venous Lymphat Disord. 2018 Nov;6(6):696-701. DOI: 10.1016/j.jvsv.2018.06.012.

5. Labropoulos N, Leon M, Volteas N, Nicolaides AN. Acute and long-term effect of elastic stockings in patients with varicose veins. Int Angiol. 1994 Jun;13(2):119-23. PMID: 7963870.

6. Sadick NS, Wasser S. Combined endovascular laser plus ambulatory phlebectomy for the treatment of superficial venous incompetence: a 4-year perspective. J Cosmet Laser Ther. 2007 Mar;9[1]:9-13. DOI: 10.1080/14764170601126640.

07. Robertson LA, Evans CJ, Lee AJ, Allan PL, Ruckley $\mathrm{CV}$, Fowkes FG. Incidence and risk factors for venous reflux in the general population: Edinburgh Vein Study. Eur J Vasc Endovasc Surg. 2014 Aug;48[2]:208-14. DOI: 10.1016/j.ejvs.2014.05.017.

08. McLafferty RB, Passman MA, Caprini JA, Rooke TW, Markwell SA, Lohr JM, et al. Increasing awareness about venous disease: The American Venous Forum expands the National Venous Screening Program. J Vasc Surg. 2008 Aug;48[2]:394-9. DOl: 10.1016/j.jvs. 2008.03.041.

09. Mansilha A, Sousa J. Pathophysiological Mechanisms of Chronic Venous Disease and Implications for Venoactive Drug Therapy. Int J Mol Sci. 2018 Jun 5;19[6]:1669. DOI: 10.3390/jims19061669.

10. Raetz J, Wilson M, Collins K. Varicose Veins: Diagnosis and Treatment. Am Fam Physician. 2019 Jun
1;99[11]:682-688. PMID: 31150188.

11. Belramman A, Bootun $R$, Lane TRA, Davies $A H$. Endovenous Management of Varicose Veins. Angiology. 2019 May;70[5]:388-396. DOI: 10. 1177/0003319718780049.

12. Proebstle TM. In der Alltagsroutine angekommen: Die endovenöse, ambulante Therapie der Varikose [Finally Daily Routine: Endovenous Outpatient Treatment of Varicose Veins]. Ther Umsch. 2018;75[8]:515-520. German. DOI: 10.1024/0040-5930/a001033.

13. Sotiris D, Pallotta G, Nittari G, Amenta F. An Original Approach for the Treatment of Varicose Veins of the Lower Limbs. J Clin Aesthet Dermatol. 2020 Aug;13(8):E59-E64. PMID: 33178385

14. Basavarajappa M, Anantharaju GS, Deepak G. Clinical study of asymptomatic deep vein thrombosis in patients with varicose veins of lower extremities. Int Surg J. 2019 Oct;6[10]:3548-53. DOI: 10.18203/2349-2902. isj20194218.

15. Nishibe T, Nishibe M, Akiyama S, Nukaga S, Ogino H, Koizumi J, Dardik A. Bioelectrical impedance analysis of leg edema and its association with venous functions in patients with saphenous varicose veins. Int Angiol. 2020;39[4]:284-289. DOI: 10.23736/S0392-9590.20. 04273-X.

16. Christenson JT, Gueddi S, Gemayel G, Bounameaux $\mathrm{H}$. Prospective randomized trial comparing endovenous laser ablation and surgery for treatment of primary great saphenous varicose veins with a 2-year follow-up. J Vasc Surg. 2010;52[5]:1234-41. DOI: 10.1016/j.jvs. 2010.06.104.

17. Pronk P, Gauw SA, Mooij MC, Gaastra MT, Lawson JA, van Goethem AR, van Vlijmen-van Keulen CJ. Randomised controlled trial comparing saphenofemoral ligation and stripping of the great saphenous vein with endovenous laser ablation [980 nm] using local tumescent anaesthesia: one year results. Eur $\mathrm{J}$ Vasc Endovasc Surg. 2010 Nov;40[5]:649-56. DOI: 10.1016/j.ejvs.2010.08.007.

18. Ash JL, Moore CJ. Laser treatment of varicose veins: order out of chaos. Semin Vasc Surg. 2010;23[2]:101-6. DOI: 10.1053/j.semvascsurg.2010.01.005.

19. Kalteis M, Berger I, Messie-Werndl S, Pistrich R, Schimetta W, Pölz W, Hieller F. High ligation combined with stripping and endovenous laser ablation of the 
great saphenous vein: early results of a randomized controlled study. J Vasc Surg. 2008 Apr;47[4]:822-9; discussion 829. DOI: 10.1016/j.jvs.2007.10.060.

20. Mozafar M, Atqiaee K, Haghighatkhah H, Taheri MS, Tabatabaey A, Lotfollahzadeh S. Endovenous laser ablation of the great saphenous vein versus high ligation: long-term results. Lasers Med Sci. 2014 Mar;29[2]:765-71. DOI: 10.1007/s10103-013-1389-z.

21. Rasmussen LH, Bjoern L, Lawaetz M, Lawaetz B, Blemings A, Eklöf B. Randomised clinical trial comparing endovenous laser ablation with stripping of the great saphenous vein: clinical outcome and recurrence after 2 years. Eur $J$ Vasc Endovasc Surg. 2010;39[5]:630-5. DOI: 10.1016/j.ejvs.2009.11.040.

22. Carradice D, Mekako Al, Mazari FA, Samuel N, Hatfield $J$, Chetter IC. Randomized clinical trial of endovenous laser ablation compared with conventional surgery for great saphenous varicose veins. $\mathrm{Br} J$ Surg. 2011 Apr;98[4]:501-10. DOI: 10.1002/bjs.7394.

23. Disselhoff BC, der Kinderen DJ, Kelder JC, Moll FL. Randomized clinical trial comparing endovenous laser with cryostripping for great saphenous varicose veins. Br J Surg. 2008;95[10]:1232-8. DOI: 10.1002/bjs.6351.

24. Doganci S, Demirkilic U. Comparison of $980 \mathrm{~nm}$ laser and bare-tip fibre with $1470 \mathrm{~nm}$ laser and radial fibre in the treatment of great saphenous vein varicosities: a prospective randomised clinical trial. Eur $\mathrm{J}$ Vasc Endovasc Surg. 2010 Aug;40[2]:254-9. DOI: 10.1016/j.ejvs.2010.04.006.

25. Woźniak W, Mlosek RK, Ciostek P. Assessment of the efficacy and safety of steam vein sclerosis as compared to classic surgery in lower extremity varicose vein management. Wideochir Inne Tech Maloinwazyjne. 2015 Apr;10[1]:15-24. DOI: 10.5114/wiitm.2015.48573.

26. Assadian A, Wickenhauser G, Hübl W, Wiltos B, Sami A, Senekowitsch C, Hagmüller GW. Traditional versus endoscopic saphenous vein stripping: a prospective randomized pilot trial. Eur J Vasc Endovasc Surg. 2008 Nov;36[5]:611-5. DOI: 10.1016/j.ejvs.2008.06.025.

27. Gloviczki P, Comerota AJ, Dalsing MC, Eklof BG, Gillespie DL, Gloviczki ML, et al. The care of patients with varicose veins and associated chronic venous diseases: clinical practice guidelines of the Society for Vascular Surgery and the American Venous Forum. J Vasc Surg. 2011 May;53[5 Suppl]:2S-48S. DOI: 10.1016/j.jvs.2011.01.079.
28. Siribumrungwong $B$, Noorit $P$, Wilasrusmee $C$, Attia $J$, Thakkinstian A. A systematic review and meta-analysis of randomised controlled trials comparing endovenous ablation and surgical intervention in patients with varicose vein. Eur J Vasc Endovasc Surg. 2012 Aug;44[2]:214-23. DOI: 10.1016/j.ejvs.2012.05.017.

29. Mallick R, Raju A, Campbell C, Carlton R, Wright D, Boswell K, Eaddy M. Treatment Patterns and Outcomes in Patients with Varicose Veins. Am Health Drug Benefits. 2016 Nov;9[8]:455-465. PMID: 28465773.

30. Bush RG, Bush P, Flanagan J, Fritz R, Gueldner T, Koziarski J, McMullen K, Zumbro G. Factors associated with recurrence of varicose veins after thermal ablation: results of the recurrent veins after thermal ablation study. ScientificWorldJournal. 2014 Jan 27;2014: 505843. DOI: $10.1155 / 2014 / 505843$.

31. McBride KD. Changing to endovenous treatment for varicose veins: how much more evidence is needed? Surgeon. 2011 Jun;9[3]:150-9. DOI: 10.1016/j.surge. 2010.11.002.

32. Kianifard B, Holdstock JM, Whiteley MS. Radiofrequency ablation [VNUS closure] does not cause neo-vascularisation at the groin at one year: results of a case controlled study. Surgeon. 2006 Apr;4[2]:71-4. DOI: 10.1016/s1479-666x[06]80032-6.

33. Winterborn RJ, Foy C, Earnshaw JJ. Causes of varicose vein recurrence: late results of a randomized controlled trial of stripping the long saphenous vein. J Vasc Surg. 2004 Oct;40[4]:634-9. DOI: 10.1016/j.jvs. 2004.07.003.

34. Nesbitt C, Bedenis R, Bhattacharya V, Stansby G. Endovenous ablation [radiofrequency and laser] and foam sclerotherapy versus open surgery for great saphenous vein varices. Cochrane Database Syst Rev. 2014 Jul 30;[7]:CD005624. DOI: 10.1002/14651858. CD005624.pub3.

35. Mousa A, El Azzazi M, Elkalla MA. Different management options for primary varicose veins in females: A prospective study. Surg Open Sci. 2019 May 20;1[1]:25-33. DOI: 10.1016/j.sopen.2019.05.002.

36. Sandhya PA, Mohil RS, Sricharan R. Randomised controlled study to compare radiofrequency ablation with minimally invasive ultrasound-guided non-flush ligation and stripping of great saphenous vein in the treatment of varicose veins. Ann R Coll Surg Engl. 2020;102[7]:525-531. DOI: 10.1308/rcsann.2020. 0116. 


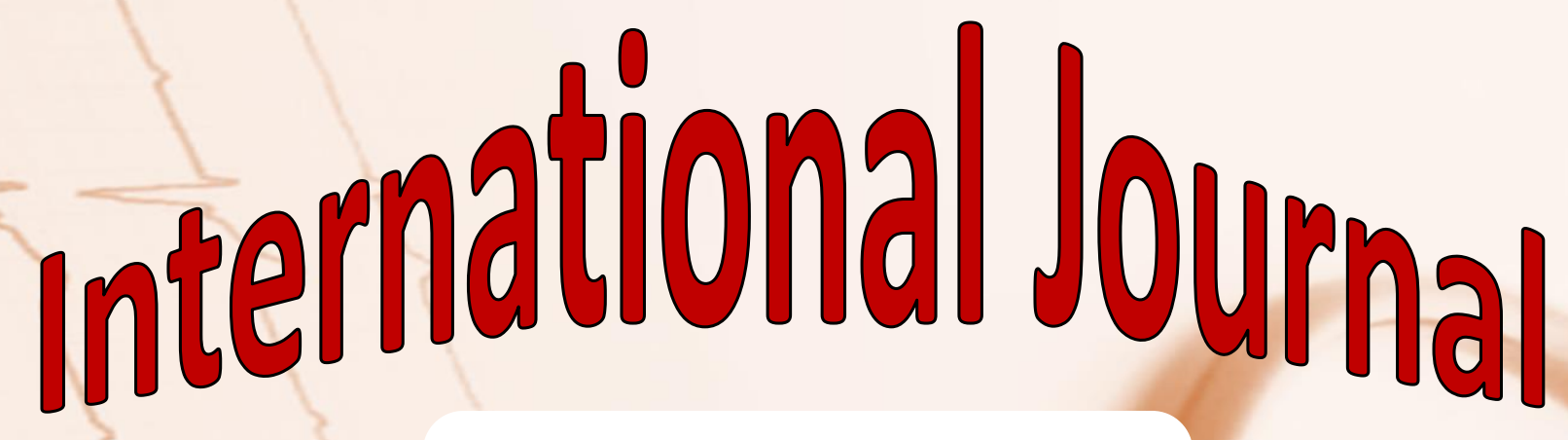

https://ijma.journals.ekb.eg/ Print ISSN: 2636-4174 Online ISSN: 2682-3780



